\title{
Na Floresta: \\ um passeio em quadrinhos pelas \\ histórias dos irmãos Grimm
}

In the forest: a walk through

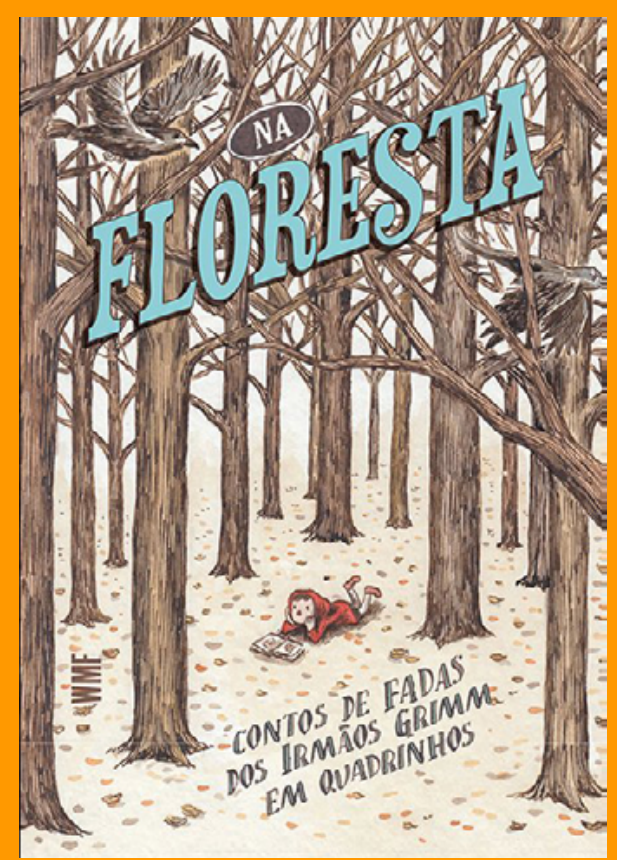
the Grimm brothers' tales in comics

\section{Jessica Ribeiro Bombonato}


RESUMO (RESENHA): PAZOS, Frederico; CABRERA, Pablo; POWER PAOLA; ELINA, María; LINIERS ; DECUR. Na Floresta: Contos de Fadas dos Irmãos Grimm em Quadrinhos. Tradução: Sergio Molina. 1. ed. São Paulo: WMF Martins Fontes, 2019.

PALAVRAS - CHAVE: contos de fada, histórias em quadrinhos, literatura infantil

ABSTRACT (REVIEW): PAZOS, Frederico; CABRERA, Pablo; POWER PAOLA; ELINA, María; LINIERS ; DECUR. Na Floresta: Contos de Fadas dos Irmãos Grimm em Quadrinhos. Tradução: Sergio Molina. 1. ed. São Paulo: WMF Martins Fontes, 2019.

KEYWORDS: fairy tales, comic book, children's literature 
"Na Floresta: Contos de Fadas" é um conjunto de curtas histórias em quadrinhos adaptadas da coletânea de contos de fadas "Contos da Infância e do Lar" originalmente publicado por Wilhelm e Jacob Grimm. A obra reúne seis quadrinistas e cartunistas latino-americanos, alguns de renome internacional como Power Paola e Liniers, e cada um desses artistas escolhe um conto para reescrevê-lo e ilustrá-lo: "João e Maria" é selecionado por Federico Pazos; "João de Ferro", por Pablo Cabrera; "Branca de Neve e Rosa Vermelha", por Power Paola; “A senhora Holle", por Decur; "Jorinda e Joringel”, por María Elina Mendez; e "O príncipe sapo", por Liniers. A reunião dessas histórias foi publicada em 2019 pela editora Martins Fontes.

Logo no título e na capa temos o grande enlace que une os seis contos: A floresta. A imagem da floresta é fortemente ligada ao desconhecido, o lugar em que coisas extraordinárias acontecem e onde destinos são traçados, desde a selva onde o poeta se perde em Inferno de Dante Alighieri, ou no bosque entre mundos de C.S. Lewis, até musicais da Broadway cheios de vida e leveza como Into the Woods. Essa escolha não é leviana; em nota antes mesmo do sumário de capítulos, temos uma citação de Jack Zipes descrevendo as mesmas propriedades fantásticas da floresta em sua obra "The Brothers Grimm: From Enchanted Forests to the Modern World". A floresta da capa, desenhada por Liniers, é carregada de imagens familiares. Uma menina de capuz vermelho lê, deitada no meio do cenário, histórias em quadrinhos (de certa forma já preparando o leitor para as interferências meta-narrativas de Liniers que aparecerão em sua adaptação), corvos negros voam por entre os galhos secos da floresta sem horizonte e trazem um sentimento de animosidade e a percepção de um lugar ermo e desconhecido. Na contracapa, ainda nessa mesma floresta vemos três figuras escondidas atrás dos troncos: uma bruxa, um lobo vestido como cavalheiro, e algum outro animal antropomorfizado de difícil reconhecimento, podendo ser um urso ou algum mamífero de pelo pardo e orelhas arredondadas. Essas figuras espreitam a menina, nos lembrando da ameaça que esses habitantes da floresta podem configurar para as crianças que se aventuram em seu território.

A primeira história que o livro nos apresenta é "João e Maria", adaptada e ilustrada por Federico Pazos. No caráter visual dessa obra, temos um traço sólido, de contornos bem definidos e cores terrosas, que remetem muito ao ambiente de uma floresta velha e aos temas de escassez e fome, as texturas são trabalhadas para intensificar características dos personagens. A madrasta tem traços grosseiros, cheia de rugas e um semblante agressivo. O pai, subserviente, 
tem uma expressão tristonha, sua boca nunca é aparente senão em um quadro, e mesmo assim é consideravelmente pequena e acanhada, o que intensifica sua personalidade. Em todos os personagens, os traços acentuam um aspecto cômico e caricato.

Essa história se liga diretamente ao cenário narrativo da capa, iniciando o conto não com o esperado "era uma vez...", mas sim "nesta floresta, havia uma casinha." A narrativa é levada principalmente pelas falas das personagens, com algumas poucas interferências do narrador para localizar o leitor e finalizar a história. A narrativa se mostra consideravelmente fiel ao conto original, incluindo até os versos que a bruxa canta, muitas vezes omitidos em adaptações. Esses versos de rima são traços marcantes do estilo dos Irmãos Grimm, que, após sua coleta de contos, adicionaram o discurso direto, a mudança do tempo verbal de presente para pretérito imperfeito, as rimas e os ditados populares incorporados aos contos, para a criação de um estilo próprio para a criança. A versão de Federico Pazos é, ao mesmo tempo, moderna e contemporânea pelo estilo visual e por um interessante equilíbrio de inovação, com expressões idiomáticas espontâneas, e pela tradição, ao se manter fiel ao conto original.

O segundo conto é "João de Ferro", adaptado e ilustrado por Pablo Cabrera. Essa versão, apesar de estar contida em uma coletânea de histórias em quadrinhos, se assemelha mais a um livro ilustrado, sem se manter em quadros, e haver ilustrações soltas. $\mathrm{O}$ traço desse conto se mostra consideravelmente mais simples, as cores se mantêm no espectro primário com poucas variações, de tons mais pastéis e menos saturados, mesmo cores mais fortes como o vermelho são apagadas. A narrativa se faz resumida em comparação ao conto, cortando diversas partes e se atendo aos aspectos mais essenciais, com pouca variabilidade estilística ou tentativas de subversão da história.

Em seguida, temos "Branca de Neve e Rosa Vermelha", ilustrado e adaptado por Power Paola, uma cartunista equatoriana conhecida por suas obras "qp" e "Vírus Tropical”, nas quais ela aborda temas como sexualidade, feminismo e identidade. Porém, em sua adaptação do conto de fadas alemão, Power Paola se afasta da sua ousadia e entrega um conto visualmente divertido, mas que ainda se atém fielmente ao original. Usando apenas as cores vermelha e branca, a cartunista alude às irmãs protagonistas.

O traço carrega uma jovialidade que não se traduz meramente como simples, não faltando painéis detalhados; ainda assim, a autora também consegue trazer uma sensação do 
inquietante, principalmente na figura do raposo, que mais se assemelha a um lobo, com seu pelo arrepiado, focinho alongado e boca cheia de dentes. As interferências do narrador são frequentes, mas a narrativa ainda é levada predominantemente através dos diálogos entre personagens, porém o narrador se faz essencial para o desfecho, sendo responsável por sumarizar os acontecimentos que se sucedem após o quadro final.

O próximo conto foi ilustrado e adaptado por Decur, e seu título é "A Senhora Holle”. Os traços são vibrantes e coloridos; simples, porém delicados, tons terrosos predominam nas partes que se passam na casa da mãe, onde a protagonista é maltratada e responsável por trabalhos pesados sem qualquer gratidão por parte da família. Os traços bruscamente se tornam alegres, com tons predominantes de verde e azul, quando a menina se vê do outro lado do poço, onde mora a misteriosa e excêntrica Senhora Holle. Ao longo da narrativa, temos diversos rostinhos felizes ou tristes em objetos e em detalhes pequenos, o que intensifica o caráter positivo ou negativo da cena. Enquanto a adaptação se mantém fiel à parte que se propõe a contar, mantendo mesmo a presença de feridas com sangue, sem sanitizá-las demais, o autor muda o final, deixando a entender uma transformação física da menina má em uma porquinha. Uma mudança notável na adaptação de Decur é o pagamento à menina preguiçosa ao atravessar o portão da Senhora Holle. Enquanto no original alemão a menina é coberta por betume, aqui o autor e ilustrador decide mudar a punição por peixes podres, talvez por sua conotação de fedor mais familiar ao leitor do que seria o balde de betume. Porém, com essa mudança, perde-se um pouco a imagem do duplo, na qual o serviço diligente resulta em ser coberto por ouro e a atitude preguiçosa resulta em ser coberto de piche, ambos mudando a aparência das duas meninas. $\mathrm{Na}$ adaptação, temos apenas o cheiro da punição e não a repulsa visual que ser coberto de piche traria. Por essa razão, talvez o ilustrador tenha escolhido uma caracterização mais óbvia da menina preguiçosa, dando a ela, antes mesmo de sua transformação final, um nariz de porco.

"Jorinda e Joringel" é a adaptação ilustrada por María Elina, e possui um traço artístico delicado, usando cores e texturas de arte tradicional majoritariamente em escala de cinza com acentos em rosa escuro. As ilustrações escapam da diagramação de quadrinhos tradicionais, ficando entre o quadrinho e o livro ilustrado. A narrativa é carregada pelo narrador com poucos momentos de fala das personagens, senão por algumas interjeições. A história se mantém 
fiel em estilo e progressão de acontecimentos, mas a autora omite os aspectos mais grotescos do original, como a velha usando de seus feitiços para transformar rapazes em pedra e moças em pássaros, e o faz para cozinhar e comê-las.

Em sua maioria, a obra completa apresenta adaptações fiéis, com poucas alterações em comparação aos contos originalmente publicados pelos irmãos Grimm, com exceção da última história "O Príncipe Sapo". Liniers mostra seu traço expressivo e rico, e o usa para intensificar as seguidas subversões que faz na narrativa original. Desde o nome, propositalmente rídiculo, da princesa protagonista (Fedora, um tipo de chapéu muito popular por sua elegância casual), a ironização da situação da mulher na concepção moderna do conto de fada - quando o rei insiste que sua filha se case, argumenta que suas irmãs estão contentes com seus esposos, enquanto os quadros nos mostram mulheres com semblantes descontentes e maridos modernos caricatos - , até o final inusitado que o autor imaginaria ser a prole do casamento da princesa com o príncipe sapo.

A adaptação toma liberdades na progressão narrativa do conto. As insistências do rei para que a princesa cumpra sua palavra ocorrem apenas uma vez, tirando o peso que a honradez e o egoísmo têm no original, e há interferências metanarrativas, em que o sapo tira personagens de outros contos de fadas de dentro do riacho. As exigências do príncipe sapo - "para começar, quero morar no castelo, comer coisas gostosas e dormir até tarde, ter um mordomo francês e um pônei branco com o nome de pompom e...” (p.85) - não condizem com as exigências do conto original — "Nada disso eu quero; nem teus vestidos, nem tuas pérolas, nem tampouco tua coroa de ouro. Mas quero que me queiras bem, que me permitas ser teu amigo e companheiro de folguedos”2(p.29) —, sendo quase axiomáticas em intenção e natureza.

As ironizações continuam mesmo na única insistência do rei para que a filha cumpra sua promessa para o sapo: “Onde já se viu os líderes do povo mentirem?”(p.87); e ainda na explicação que o príncipe sapo, agora humano, dá para a princesa sobre os motivos de sua

2 Traduzido do alemão: "Deine Kleider, deine Perlen und Edelsteine und deine goldene Krone, die mag ich nicht: aber wenn du mich liebhaben willst, und ich soll dein Geselle und Spielkamerad sein” Grimm, J. e W. Kinder und Hausmärchen - Ausgabe letzter Hand mit den Originalmerkungen der Brüder Grimm. Philipp Reclam jun. Stuttgart. 2010. 
condição animal, ironizando dessa vez a própria narrativa original: "E só te livrarás do feitiço se uma princesa perder uma bola dourada, e tu a recuperares, mas ela te trair, e ainda assim a encontrares e, depois de comer e de dormir na sua cama, ela te esborrachar numa parede. As chances que isso aconteça são...ínfimas! HUÁ HUÁ HUÁ!” (p.90).

Apesar de sarcástico e ironizador, o autor traz um olhar moderno para o conto por meio da subversão dos finais esperados de um relato tão conhecido como esse. Por outro lado, mesmo omitindo a segunda metade do conto, em que o servo do príncipe amaldiçoado quebra as bandas de metal em volta de seu coração, Liniers se mantém fiel ao espírito transformador da floresta que é trabalhado na capa e nas notas iniciais.

“Na Floresta: Contos de Fadas dos Irmãos Grimm” é uma coletânea diversa que aborda contos famosos e outros mais obscuros. Cada ilustrador agrega um significado diferente para cada um de seus contos, intensificando os efeitos das narrativas. De fato, a floresta é um lugar onde destinos são alterados, como posto na citação inicial, e um dos destinos transformados é o da própria narrativa final. 